\title{
Kajian Peluang Pemanfaatan Bioetanol Sebagai Bahan Bakar Utama Kendaraan Masa Depan Di Indonesia
}

\section{Study Of Bioethanol Utilization Opportunities As The Main Fuel For Future Vehicles In Indonesia}

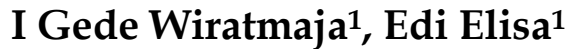 \\ 1Program Studi Pendidikan Teknik Mesin, Universitas Pendidikan Ganesha, Singaraja, Indonesia \\ e-mail: wiratmaja@undiksha.ac.id, edi.elisa@undiksha.ac.id
}

\begin{abstract}
Abstrak
Kelangsungan penggunaan bioetanol sebagai aditif dari bahan bakar bensin yang bersumber dari energi fosil khususnya di Indonesia cukup mendapatan tantangan berat, apalagi untuk menjadikan bioetanol sebagai bahan bakar utama pengganti bahan bakar fosil dimasa depan. Artikel ini ditulis berdasarkan hasil kajian dan studi literatur yang berkaitan dengan pemanfaatan bioetanol sebagai salah satu energi alternatif. Metode penelitian meliputi pengambilan dan kompilasi data sekunder serta berusaha memberikan suatu gagasan solusi dalam mengatasi permasalahan yang timbul yang pada akhirnya dari analisis data ditarik suatu kesimpulan dari keseluruhan studi literatur yang telah dilakukan.

Dari kajian literatur diperoleh kelebihan dari bioetanol yang cukup signifikan yaitu mampu meningkatkan unjuk kerja dari mesin terutama pada putaran mesin yang tinggi. Penggunaan bioetanol juga mampu menurunkan emisi $\mathrm{CO}$, dan $\mathrm{CO}_{2}$. Harus pula dilihat beberapa kekurangannya antara lain bioetanol bereaksi dengan logam seperti magnesium dan aluminium. Selanjutnya dari sisi ekonomi untuk memasarkan bioetanol dengan harga rendah cukup sulit untuk dilakukan. Dari segi penyediaan bahan baku yang bersumber dari tanaman yang mengandung gula dikhawatirkan akan memicu persaingan antara ketersediaan bahan baku dengan ketersediaan pangan.

Salah satu solusi dalam menjamin keberlangsungan pemenuhan bahan baku pembuatan bioetanol adalah melalui pemanfaatan bahan-bahan berlignosellulosa yang memiliki struktur gula sederhana dan dapat dikonversi menjadi etanol. Dari sisi ketersediaan masih cukup melimpah, murah dan masih belum banyak dimanfaatkan dalam skala besar.
\end{abstract}

Kata Kunci : Bioetanol, Energi Terbarukan, Unjuk Kerja.

\begin{abstract}
The continuity of the use of bioethanol as an additive from gasoline fuel sourced from fossil energy, especially in Indonesia, is getting tough challenges, especially to make bioethanol as the main fuel for future fossil fuels. This article is written based on the results of studies and literature studies relating to the utilization of bioethanol as an alternative energy. Research methods conducted include capturing and compiling secondary data and attempting to provide an idea of solutions in addressing the emerging issues and in the end can drawn a conclusion of the overall literature study that has been conducted before.
\end{abstract}


From the study of literature acquired advantages of bioethanol is quite significant that is able to improve the engine performance especially in the high engine rotation. The use of bioethanol is also able to reduce $\mathrm{CO}$, and $\mathrm{CO}_{2}$ emissions. It should also be seen some disadvantages among other bioethanol can react with metals such as magnesium and aluminum. Furthermore, from the economic side to market bioethanol with a low price is quite difficult to do. In terms of provision of raw materials sourced from plants containing sugar is feared there will be competition between the availability of raw materials of bioethanol with food availability for human life.

One solution in ensuring the continuity of the fulfillment of bioethanol making raw materials is through the use of lignosellulosic materials containing simple sugar structures that can be transformed into ethanol where availability is still abundant, inexpensive and still not widely utilized in large scale.

\section{Keywords: Bioethanol, Engine Performance, Renewable Energy}

\section{PENDAHULUAN}

Sebagaimana kita ketahui sektor energi merupakan sektor yang mempunyai peranan yang begitu vital bagi eksistensi sebuah negara dan penting dalam usaha pencapaian tujuan nasional. Energi merupakan salah satu penyangga penting dalam suatu sistem pertahanan sebuah negara. Energi juga merupakan sesuatu yang mutlak dibutuhkan dalam melaksanakan pembangunan yang berkelanjutan serta merupakan pendukung utama bagi kelangsungan roda ekonomi nasional, sehingga ketahanan energi merupakan syarat mutlak bagi negara ini untuk bisa bergerak ke depan. Selain untuk memenuhi kebutuhan energi nasional, sektor energi juga mempunyai peran penting lainnya yaitu sebagai sumber devisa negara, utamanya dari minyak bumi dan gas alam (Fitriyatus Sa'adah, Fauzi, \& Juanda, 2017).

Sektor energi mempunyai peranan penting dalam menjalankan roda perekonomian nasional. Ketersediaan energi merupakan faktor yang sangat penting dalam menunjang keberlangsungan pembangunan negara. Seiring dengan peningkatan pembangunan diberbagai bidang, pertumbuhan ekonomi dan penduduk maka kebutuhan akan energi akan terus meningkat dari waktu ke waktu (Elinur, Priyarsono, \& Firdaus, 2010).

Kebutuhan energi Indonesia dari tahun ke tahun terus mengalami peningkatan seiring dengan meningkatnya pertumbuhan ekonomi dan jumlah penduduk. Berdasarkan data dari Kementerian ESDM RI, konsumsi energi tertinggi Indonesia berasal dari bahan bakar fosil dengan tingkat konsumsi hampir mencapai 95\% . Dari tingkat konsumsi tersebut, hampir 50\% nya merupakan Bahan Bakar Minyak (BBM), sehingga tidak mengherankan jika konsumsi energi pada sektor transportasi akan mengalami peningkatan dalam beberapa tahun kedepan. Sementara itu konsumsi bahan bakar fosil di Indonesia yang terus meningkat tidak diiringi dengan peningkatan kapasitas produksi dan ketersediaan sumber daya.

Ketersediaan energi (energy supply) merupakan suatu hal yang selalu menjadi perhatian semua negara di dunia dikarenakan tingkat kesejahteraan manusia dalam kehidupan modern saat ini sangat berhubungan dengan jumlah dan mutu energi yang dimanfaatkan. Energi fosil yang terdiri atas batubara, minyak bumi, dan gas alam masih menjadi sumber energi yang utama sebagai penggerak roda perekonomian di Indonesia. Dilain pihak keberlangsungan ketersediaan energi fosil dikhawatirkan akan terancam seiring dengan berkurangnya sumber daya alam tak terbaharukan.

Kekhawatiran akan habisnya cadangan energi fosil semakin menjadi - jadi setelah muncul prediksi bahwa habisnya cadangan energi fosil akan terjadi dalam waktu tidak lama lagi. Data pada Kementerian ESDM menunjukkan bahwa cadangan batu bara Indonesia saat ini berada diangka sekitar 7,3-8,3 miliar ton dan diperkirakan akan habis pada tahun 2036. Demikian pula dengan cadangan minyak bumi yang sekarang tinggal 4,7 miliar barel dan 
diprediksi akan habis pada tahun 2028. Sementara itu bahan bakar gas malah diperkirakan lebih cepat lagi habisnya, yaitu pada tahun 2027 atau sekitar tujuh tahun dari sekarang.

Sementara itu dampak dari penggunaan energi fosil yang terus meningkat khususnya pada moda transportasi akan berakibat pada semakin tingginya tingkat pencemaran udara yang akan berdampak negatif terhadap lingkungan seperti menipisnya lapisan ozon yang mengakibatkan terjadinya pemanasan global, gangguan pada kesehatan manusia seperti infeksi pada saluran pernafasan, kanker kulit, hingga kerusakan lingkungan. Dari hal ini dapat terlihat kaitan antara transportasi dengan lingkungan yang dilihat dari masalah perilaku manusia terhadap lingkungannya (Sudrajad, 2006).

Dalam usaha mengurangi ketergantungan terhadap energi fosil khususnya bahan bakar minyak yang akan habis karena depositnya terbatas maka sangat diperlukan upaya peningkatan pemanfaatan energi lain terutama pada sektor transportasi, di antaranya dengan penggunaan biofuel, khususnya bioetanol yang merupakan sumber energi alternatif yang dapat diperbaharui juga ramah lingkungan.

Beberapa langkah - langkah kebijakan dalam upaya pemanfaatan energi terbarukan untuk mendukung subtitusi BBM non renewable energy resources sudah dilakukan oleh pemerintah, salah satunya adalah dengan kebijakan diversifikasi energi dengan melakukan upaya penggantian BBM dengan Bio-diesel (Bio-Solar) dan Bio-Etanol. Hal ini diharapakan menjadi salah satu upaya penganekaragaman penyediaan dan pemanfaatan dari berbagai sumber energi dalam rangka optimalisasi penyediaan energi.

Negara yang sukses dalam menerapkan kebijakan diversifikasi energi dapat dilihat pada Amerika Serikat dan Brazil yang mana merupakan negara yang sukses menerapkan bioetanol sebagai aditif dalam bahan bakar kendaraan. Amerika Serikat dan Brazil juga merupakan negara dengan tingkat produksi bioetanol tertinggi di dunia, dimana sepanjang tahun 2018 Amerika Serikat berhasil memproduksi 16.1 miliar gallon bioetanol, sementara Brazil berada di posisi kedua dengan total produksi 7,95 miliar gallon.

Selain itu mayoritas jenis kendaraan di Brazil adalah flexible-fuel vehicle dimana kendaraan jenis ini sudah dimodifikasi sedemikian rupa sehingga dapat mengkonsumsi bioetanol murni. Hal ini terjadi dkarenakan sejak tahun 1976, pemerintah Brazil telah mengeluarkan kebijakan bahwa etanol wajib digunakan sebagai campuran bahan bakar kendaraan dengan perbandingan $22 \%$ etanol dan $78 \%$ bensin yang biasa disebut dengan E22. Perbandingan ini meningkat di tahun 2015 dimana Brazil sudah menggunakan bioetanol dengan perbandingan $25 \%$ etanol dan $75 \%$ bensin (E25).

Di Indonesia, Kementerian Energi dan Sumber Daya Mineral (KESDM) telah mengeluarkan Peraturan Menteri ESDM Nomor 12 Tahun 2015 yang di dalamnya menyatakan bahwa penggunaan bioetanol E5 diwajibkan pada tahun 2020 dengan komposisi $5 \%$ etanol dan 95\% bensin dan akan meningkat ke E20 pada tahun 2025. Namun dalam perjalanannya rencana tersebut menghadapi berbagai kendala seperti penolakan dari para pengusaha nasional, biaya produksi etanol yang sangat tinggi, serta terbatasnya pasokan dan persediaan bahan baku membuat bioetanol menjadi kurang kompetitif sebagai bahan bakar alternatif untuk kendaraan bermotor.

Dari hal ini dapat disimpulkan bahwa kelangsungan penggunaan bioetanol sebagai komplementer/pelengkap dari bahan bakar minyak yang bersumber dari energi fosil khususnya di Indonesia cukup mendapatan tantangan berat, apalagi nantinya untuk menjadikan bioetanol sebagai bahan bakar utama pengganti bahan bakar fosil dimasa depan sepertinya masih belum menemuan titik terang. Untuk itu sangat diperlukan suatu analisis pemetaan masalah demi memberikan suatu gagasan solusi pemecahannya. 


\section{METODE}

Artikel ini ditulis berdasarkan hasil kajian dan studi literatur yang berkaitan dengan pemanfaatan bioetanol sebagai salah satu energi alternatif ramah lingkungan pengganti bahan bakar minyak yang bersumber dari energi fosil. Metode penelitian meliputi pengambilan dan kompilasi data sekunder berupa situs resmi yang diakses secara online, review jurnal yang terkait dengan bagaimana pengaruh penambahan bioetanol pada bensin terhadap unjuk kerja kendaraan bermotor yang meliputi daya, torsi dan konsumsi bahan bakar serta pengaruhnya terhadap emisi gas buang.

Selanjutnya dilakukan analisis serta pembahasan mengenai kelangsungan dan kelayakan bioetanol sebagai bahan bakar utama, bukan hanya sebagai aditif bahan bakar bensin pada kendaraan bermotor serta berusaha memberikan suatu gagasan solusi dalam mengatasi permasalahan yang timbul yang pada akhirnya dari analisis data bermuara pada suatu kesimpulan dari keseluruhan studi literatur yang telah dilakukan.

\section{HASIL DAN PEMBAHASAN}

Indonesia sebagai negara yang kaya dengan sumber daya alam memiliki kesempatan yang luas untuk pengembangan bioetanol sebagai pengganti energi fosil yang semakin lama cadangannya semakin menipis. Pemerintah telah memperkuat pengembangan bioetanol ini dengan membuat Peraturan Presiden Republik Indonesia Nomor 5 Tahun 2006 yang diikuti dengan peraturan Menteri ESDM Nomor 12 Tahun 2015 tentang Kebijakan Energi Nasional untuk mengembangkan sumber energi alternatif sebagai pengganti bahan bakar minyak yang bersumber dari energi fosil (Warsa dalam Arlianti, 2018).Etanol adalah zat cair mudah larut yang dihasilkan dari fermentasi glukosa dan untuk meningkatkan kemurniannya biasanya dilanjutkan dengan proses destilasi. Etanol merupakan kependekan dari etil alkohol dengan rumus kimia $\left(\mathrm{C}_{2} \mathrm{H}_{5} \mathrm{OH}\right)$, massa jenis sebesar $0,7939 \mathrm{~g} / \mathrm{mL}$, dan titik didihnya sebesar $78,320^{\circ} \mathrm{C}$ pada tekanan $766 \mathrm{mmHg}$, serta mempunyai panas pembakaran $7093.72 \mathrm{kkal}$. (Novendri, 2018).

Dalam perkembangannya, produksi bioetanol yang paling banyak digunakan adalah hasil produksi yang diperoleh melalui metode fermentasi dimana proses ini akan menghasilkan alkohol dengan kadar yang cukup rendah. Untuk meningkatkan kadar etanol agar dapat mencapai Fuel Grade Ethanol (FGE) dengan kadar 99.5\% dibutuhkan proses lanjutan berupa penyulingan (distillation) dan dehidrasi (dehydration). Adapun beberapa kelebihan dari bioetanol yang dinilai cukup signifikan yaitu mampu meningkatkan unjuk kerja dari mesin kendaraan. Hal ini dapat dilihat pada pemakaian biogasoline dengan rasio campuran bensin dan bioetanol dengan komposisi (90:10) yang memberikan nilai torsi dan daya lebih tinggi serta konsumsi bahan bakar spesifik yang lebih rendah dibandingan dengan penggunaan bensin murni terutama pada putaran mesin yang tinggi (Wiratmaja, 2010a).

Hal ini dikarenakan bioetanol memiliki nilai research oktan number (RON) 116 - 129, yang relatif lebih tinggi dibandingkan bahan bakar bensin jenis premium yang mempunyai nilai oktan RON 88. Dengan nilai RON yang tinggi, bioetanol yang dapat berfungsi sebagai aditif mampu bekerja dengan baik dalam mendongkrak nilai oktan (octane booster) bahan bakar dengan oktan rendah sehingga berdampak positif terhadap efisiensi dan daya mesin, khususnya bagi mesin kendaraan dengan rasio kompresi tinggi serta menghindari terjadinya detonasi pada saat proses pembakaran di dalam mesin.

Tabel 1. Sumber dan Standar Kesehatan Emisi Gas Buang Kendaraan (Ismiyati, Marlita, E Saidah, 2014).

\begin{tabular}{ll}
\hline Pencemar & Keterangan \\
\hline Karbon monoksida (CO) & Standar kesehatan: $10 \mathrm{mg} / \mathrm{m} 3(9 \mathrm{ppm})$ \\
Oksida sulfur (S0x) & Standar kesehatan: $80 \mathrm{ug} / \mathrm{m} 3(0.03 \mathrm{ppm})$ \\
\hline
\end{tabular}




\begin{tabular}{ll}
\hline Partikulat Matter & $\begin{array}{l}\text { Standar kesehatan: } 50 \mathrm{ug} / \mathrm{m} 3 \text { selama } 1 \\
\text { tahun; } 150 \mathrm{ug} / \mathrm{m} 3\end{array}$ \\
Okdida Nitrogen (N0x) & $\begin{array}{l}\text { Standar kesehatan: } 100 \mathrm{pg} / \mathrm{m} 3 \text { (0.05 } \\
\text { ppm) selama } 1 \text { jam }\end{array}$ \\
Ozon (03) & $\begin{array}{l}\text { Standar kesehatan: } 235 \mathrm{ug} / \mathrm{m} 3(0.12 \\
\text { ppm) selama 1 jam }\end{array}$ \\
\hline
\end{tabular}

Dari tabel 1 dapat dilihat ambang batas dari kadar emisi gas buang kendaraan. Dari proses pembakaran yang tidak sempurna dihasilkan emisi gas buang berupa HC (Hidrokarbon), $\mathrm{CO}$ (Karbon Monosikda), $\mathrm{CO}_{2}$ (Karbon Dioksida ), $\mathrm{O}_{2}$ (Oksigen) dan senyawa NOx (Nitrogen Oksida). Dari hasil pengujian emisi gas buang diambil suatu kesimpulan bahwa pada variasi putaran mesin, dimana semakin tinggi putaran mesin akan menghasilkan emisi $\mathrm{HC}$ yang semakin tinggi dan menurunkan emisi $\mathrm{CO}$, dan $\mathrm{CO}_{2}$. Semakin banyak konsentrasi bioetanol yang digunakan akan menghasilkan emisi HC yang semakin tinggi dan emisi CO, dan $\mathrm{CO}_{2}$ yang semakin menurun (Ruri Octaviani,Moh Irsyad, 2010).

Tabel 2. Perbandingan Sifat Fisika Antara Ethanol Dengan Bensin (www.afdc.doe.gov dalam Wiratmaja, 2010b)

\begin{tabular}{|c|c|c|}
\hline Property & Ethanol & Gasoline \\
\hline Chemical formula & $\mathrm{C}_{2} \mathrm{H}_{5} \mathrm{OH}$ & $\mathrm{C}_{4} \mathrm{sd} \mathrm{C}_{10}$ \\
\hline \multicolumn{3}{|l|}{ Composition $\%$ weight } \\
\hline Carbon & 52.2 & $85-88$ \\
\hline Hydrogen & 13.1 & $12-15$ \\
\hline Oxygen & 34.7 & 0 \\
\hline \multicolumn{3}{|l|}{ Octane Number } \\
\hline Research Octane & 108 & $90-100$ \\
\hline Motor Octane & 92 & $81-90$ \\
\hline Density (lb/gal) & 6.61 & $6.0-6.5$ \\
\hline Boiling temp. $(\circ \mathrm{F})$ & 172 & $80-437$ \\
\hline Freezing Point $\left({ }^{\mathrm{o}} \mathrm{F}\right)$ & -173.22 & -40 \\
\hline Flash Point $\left({ }^{\circ} \mathrm{F}\right)$ & 55 & -45 \\
\hline Auto Ignition Temp. $\left({ }^{\circ} \mathrm{F}\right)$ & 793 & 495 \\
\hline \multicolumn{3}{|l|}{ Heating value } \\
\hline Higher (Btu/gal) & 84100 & 124800 \\
\hline Lower ( Btu / gal) & 76000 & 115000 \\
\hline Spesific heat Btu/lb ${ }^{\circ} \mathrm{F}$ & 0.57 & 0.48 \\
\hline Stoichiometric air/ fuel, weight & 9 & 14.7 \\
\hline
\end{tabular}

Dari perbandingan sifat fisika bioetanol terhadap bensin seperti yang ditampilkan pada tabel 2, dapat dilihat bahwa bioetanol memiliki sifat - sifat fisika yang mendekati dari sifat - sifat fisika dari bensin atau dapat dikatakan berada pada interval sifat fisika dari bensin sehingga penggunaan bioetanol sebagai bahan bakar utama haruslah mendapatkan kajian dan perhatian yang lebih serius dari pemerintah selaku pemangku kebijakan agar penggunaan bioetanol tidak hanya sekedar sebagai aditif atau sebagai campuran bahan bakar bensin, tapi memiliki kemampuan sebagai bahan bakar utama kendaraan dimasa depan.

Selanjutnya harus dilihat pula beberpa kekurangan dari bioetanol dibandingkan bensin yaitu pada kondisi temperatur rendah, mesin dengan bahan bakar bioetanol akan lebih 
sulit melakukan starter serta fakta bahwa bioetanol bereaksi dengan logam seperti magnesium dan aluminium sehingga dapat merusak komponen kendaraan yang terbuat dari logam tersebut.(Restu Setiawati, Rafika Sinaga, Kurnia Dewi, 2013).

Hal ini dikarenakan etanol merupakan bahan bakar yang sangat mudah teroksidasi, sehingga sangat memungkinkan untuk terbentuk uap dan titik - titik air pada tangki dan pipapipa saluran bahan bakar pada kendaraan. Uap dan titik air tersebut dapat menyebabkan korosi pada tangki dan saluran bahan bakar sehingga penggunaan etanol akan mempercepat terjadinya korosi pada tangki dan saluran bahan bakar. Sebagai langkah solusi, haruslah dilakukan kajian dan modifikasi terhadap material kendaraan khususnya saluran bahan bakar dan tangki bahan bakar dimana material yang digunakan sebelumnya digantikan dengan material yang lebih tahan terhadap korosi.(Fahmi \& Setiyo, 2015).

Selanjutnya kendala dari sisi ekonomi dimana dalam proses destilasi bioetanol dalam usaha mendapatkan kadar kemurnian yang lebih tinggi dapat dikatakan terbilang rumit dan memerlukan biaya tinggi sehingga untuk memasarkan bioetanol dengan harga rendah cukup sulit untuk dilakukan sehingga dipastikan akan adanya disparitas harga bioetanol dengan bensin yang cukup tinggi, dimana selisih harga tersebut tercatat sempat mencapai Rp 4.150/liter pada bulan Juni 2016. Tentunya disparitas harga yang tinggi ini, membuat bioetanol menjadi kurang diminati untuk dikembangkakan lebih lanjut karena dianggap kurang ekonomis.

Dari segi penyediaan bahan baku pembuatan bioetanol yang bersumber dari tanaman yang mengandung gula seperti tebu dan singkong juga rentan menjadi penghalang bagi perkembangan bioetanol itu sendiri. Hal ini disebabkan tebu dan singkong merupakan salah satu produk utama pangan, sehingga dengan meningkatnya penggunaan bioetanol sebagai salah satu sumber energi alternatif otomatis akan meningkatkan permintaan bahan baku sehingga dikhawatirkan akan terjadi persaingan antara ketersediaan bahan baku untuk pangan, pakan, dan untuk sumber energi sehingga berdampak terhadap kealngsungan hidup manusia.

Selain itu, dalam usaha untuk menggantikan semua kebutuhan bahan bakar minyak dunia saat ini dengan etanol maka diperlukan luas lahan pertanian yang sangat luas untuk menghindari sifat intermitten bahan bakar alternatif sehingga membuka peluang terjadinya pembabatan hutan dalam skala besar. Melihat fakta bahwa saat ini di berbagai negara didunia telah menunjukkan indikasi adanya krisis pada sektor pangan dan energi, maka sangat perlu untuk segera mencari sumber bahan baku pembuatan bioetanol yang lebih aman.(Wiratmaja, Kusuma, \& Winaya, 2011).

Dari beberapa kekurangan bioetanol tersebut haruslah dapat segera ditemukan solusinya agar penggunaan bioetanol sebagai bahan bakar tidak cuma berhenti pada pengaplikasiannya sebagai bahan bakar alternatif dan sebagai aditif bahan bakar bensin namun mampu berdiri sendiri sebagai bahan bakar alternatif untuk sekarang ini dan menjadi bahan bakar utama dimasa depan seiring dengan habisnya cadangan bahan bakar yang berbasis pada energi fosil.

Salah satu solusi yang dapat digunakan dalam mengatasi ketersediaan bahan baku bioetanol adalah melalui usaha pembuatan bioetanol generasi kedua melalui pemanfaatan bahan-bahan berlignosellulosa yang mengandung struktur gula sederhana yang dapat diubah menjadi etanol yang mana ketersediaannya masih melimpah, murah dan masih belum banyak dimanfaatkan dalam skala besar.

Beberapa penelitian sebelumnya telah membahas tentang pemanfaatan bahan - bahan berlignoselusosa dalam usaha pembuatan etanol generasi kedua, salah satunya melalui pemanfaatan rumput laut untuk dijadikan sumber bahan baku utama dalam produksi 
bioetanol yang dilakukan melalui tahapan proses hydrolisis dan fermentasi (Offei, Mensah, Thygesen, \& Kemausuor, 2018).

\section{KESIMPULAN DAN SARAN}

Dari komparasi kelebihan dan kekurangan dari penggunaan bioetanol sebagai bahan bakar alternatif dimasa sekarang dan peluang menjadi bahan bakar utama dimasa depan dapatlah dilihat dari aspek teknis dan non teknis. Dari sisi teknis peluang penggunaan bioetanol sebagai bahan bakar utama pengganti bahan bakar bensin yang bersumber dari energi fosil dimasa depan cukup besar dikarenakan sifat - sifat fisika bioetanol yang mendekati sifat - fisika bahan bakar bensin. Namun tetap ada pekerjaan rumah utama bagi para pemangku kebijakan yaitu penyelesaian permasalahan non teknis seperti penyelesaian kontinuitas ketersediaan bahan baku sampai dengan usaha menekan harga jual bioetanol di pasaran yang harus diselesaikan sesegera mungkin dan berpacu dengan waktu seiring dengan akan habisnya cadangan energi fosil yang tidak terbaharukan.

\section{DAFTAR RUJUKAN}

Arlianti, L. (2018). Bioetanol sebagai sumber green energy alternatif yang potensial Di Indonesia A review article. Jurnal Keilmuan dan Aplikasi Teknik UNISTEK, 5(1), 16-22.

Elinur, Priyarsono, D. S., \& Firdaus, M. T. M. (2010). Perkembangan konsumsi dan penyediaan energi dalam perekonomian Indonesia. Indonesian Journal of Agricultural Economics (IJAE), 2(1), 97-119.

Fahmi, L., \& Setiyo, M. (2015). Pengaruh campuran ethanol pada laju korosi tangki bahan bakar). Semnastek, (November), 1-6. Retrieved from jurnal.ftumj.ac.id/index.php/semnastek

Fitriyatus Sa'adah, A., Fauzi, A., \& Juanda, B. (2017). peramalan penyediaan dan konsumsi bahan bakar minyak indonesia dengan model sistem dinamik prediction of fuel supply and consumption in Indonesia with system dynamics model. Jurnal Ekonomi dan Pembangunan Indonesia, 17(2), 118-137. doi:10.21002/jepi.v17i2.661

Ismiyati, Marlita, D., \& Saidah, D. (2014). Pencemaran udara akibat emisi gas buang kendaraan bermotor. Jurnal Manajemen Transportasi \& Logistik (JMTransLog), 01(03), 241-248. doi:10.25292/j.mtl.v1i3.23

Novendri, Y. (2018). Pengaruh penambahan aditif etanol pada bensin ron 88 dan ron 92 terhadap prestasi mesin. Jurnal Konversi Energi Dan Manufaktur UNJ, 1(April), 33-39. doi:https://doi.org/10.21009/JKEM.5.1.6

Octaviani, R., Irsyad, M., \& Reksowardojo, I. K. (2010). Pengaruh penambahan bioetanol terhadap konsentrasi emisi gas Hc , Co , Dan Co 2 pada motor 2 langkah. Jurnal Teknik Lingkungan, 16(2), 173-184.

Offei, F., Mensah, M., Thygesen, A., \& Kemausuor, F. (2018). Seaweed bioethanol production: A process selection review on hydrolysis and fermentation. Fermentation, 4(4), 1-18. doi:10.3390/fermentation4040099

Setiawati, D. R., Sinaga, A. R., \& Dewi, T. K. (2013). Proses pembuatan bioetanol dari kulit pisang kepok. Jurnal Teknik Kimia, 19(1), 9-15. 
Wiratmaja, I. G. (2010a). Analisa unjuk kerja motor bensin akibat pemakaian biogasoline. Jurnal Ilmiah Teknik Mesin Cakram, 4(1), 16-25.

Wiratmaja, I. G. (2010b). Pengujian karakteristik fisika biogasoline sebagai bahan bakar alternatif pengganti bensin murni. Jurnal Energi Dan Manufaktur, 4(2), 145-154. doi:https://doi.org/10.24843/JEM.2020.v13.i01

Wiratmaja, I. G., Kusuma, I. G. B. W., \& Winaya, I. N. S. (2011). Pembuatan etanol generasi kedua dengan memanfaatkan limbah rumput laut eucheuma cottonii sebagai bahan baku. Jurnal Energi Dan Manufaktur, 5(1), 75-84. 